\title{
From Humans to Dogs and Back: The Translational Lesson of Metronomic Chemotherapy
}

\author{
${ }^{1}$ Alessio Pierini, ${ }^{2}$ Guido Bocci, ${ }^{1}$ Mario Giorgi, ${ }^{3}$ Helen Owen and ${ }^{1}$ Veronica Marchetti \\ ${ }^{1}$ Department of Veterinary Sciences, University of Pisa, \\ Via Livornese (lato monte), San Piero a Grado, 56010, Pisa \\ ${ }^{2}$ Department of Clinical and Experimental Medicine, Division of Pharmacology, \\ University of Pisa and Istituto Toscano Tumori (ITT), Via Alderotti 57/n, Florence, Italy \\ ${ }^{3}$ School of Veterinary Science, \\ The University of Queensland, Gatton Campus, Gatton, Queensland, 4343, Australia
}

Received 2012-10-31, Revised 2012-12-16; Accepted 2012-12-31

\begin{abstract}
The main priority in veterinary oncology is to maintain patient quality of life. It is important that new chemotherapy strategies aim to minimize side effects, thus making the treatment attractive for owners as well as their pets. Metronomic chemotherapy has been shown to have an important stabilizing effect on human cancer (including chemotherapy-resistant disease) resulting in prolonged clinical benefit. In addition, this form of treatment has been shown to have positive effects on the quality of life of patients with various types of cancer. These positive effects are obtained without any indication of high grade toxicity. Moreover, low cost and oral administration (which reduces the need for hospitalization and enables patients to stay at home longer) are key characteristics of this schedule, offering important advantages in frail subgroups of patients (e.g., old patients) for whom new therapeutic options are greatly needed. From another perspective, use of metronomic chemotherapy in dogs could reveal new and innovative schedules that could be applied to humans. Veterinary oncology cases treated with metronomic schedules represent the unique opportunity to ethically investigate novel drugs or combination treatments that may be highly translatable to the human community. The aim of the present review was to describe how this new form of treatment has evolved in canine patients thus far.
\end{abstract}

Keywords: Metronomic Chemotherapy, Antiangiogenic Therapy, Oncology, Cancer

\section{INTRODUCTION}

The prevalence of cancer in dogs has increased in recent years. This may be the result of an actual increase in cancer incidence, an increase in the population of dogs at risk for the development of cancer and/or increased awareness and interest in the pet-owning community to pursue diagnostic and treatment options. Advances in the care of animals has allowed dogs to live longer due to better nutrition, vaccination for common infectious diseases, leash laws that limit automobile deaths and the availability of more sophisticated diagnostics and treatments for many ailments previously considered to be life-threatening. However, the improved general health of pets has resulted in an increase in age-related diseases, including cancer (Paoloni and Khanna, 2007; Giorgi, 2012).

As in normal tissues, tumors require nutrients and oxygen and the removal of carbon dioxide and catabolites, these functions are accomplished by the vasculature. During embryogenesis, blood vessels develop via two processes: Vasculogenesis, whereby endothelial cells differentiate from progenitor cell types; and angiogenesis, in which new capillaries sprout from existing vessels. The vasculature is quiescent in the normal adult mammal, except for the predictable changes

Corresponding Author: Mario Giorgi, Department of Veterinary Sciences, University of Pisa, Via Livornese (lato monte), San Piero a Grado, 56010, Pisa 
that occur during the female reproductive cycle (ovulation, menstruation, implantation, pregnancy). In contrast, in tumor progression activation of angiogenesis is permanent with continuous sprouting of new blood vessels that can support and supply nutrients to the neoplastic growth (Hanahan and Folkman, 1996). Historically, angiogenesis was only considered important in the rapid growth phase of the tumor, however more recent surveys attribute great importance to angiogenesis in microscopic premalignant lesions (Hanahan and Weinberg, 2011). Hence, there is a need to develop antiangiogenic strategies to combine with conventional antineoplastic chemotherapy protocols. Such a multifaceted attack will increase the likelihood of success in the fight against malignant tumors.

The importance of angiogenesis in tumor growth was first described by Folkman (1971), however the efficacy of some forms of antiangiogenic chemotherapy was not described for another twenty years (Kerbel, 1991). The term angiogenesis refers to endothelial sprouting or Intussusceptive Microvascular Growth (IMG) and applies to the formation of capillaries starting from pre-existing vessels. Nutrients and oxygen delivered via blood vessels are crucial for the survival and function of cells and for this reason, cells further than 100 micron from a capillary will not be viable (Ribatti et al., 2009). Both solid and haematological tumors have some angiogenic capabilities and their growth, invasiveness and metastatic potential are angiogenesis-dependent (Ribatti et al., 2007).

The Vascular Endothelial Growth Factor (VEGF) is certainly one of the most studied of the proangiogenic factors. Different isoforms of its high affinity tyrosinekinase receptor have been identified: VEGFR-1 (or Flt1), VEGFR-2 (or KDR/Flk-1) and VEGFR-3 (or Flt-4) (Ribatti et al., 2007). VEGFR-2 is responsible for the majority of the angiogenic and permeability-enhancing effects of VEGF (Giovannini et al., 2010). Thus, both VEGF and VEGFR-2 have been logical candidates for new therapeutic approaches, based on their functional relevance to cancer pathophysiology (Ferrara et al., 2003). Another mechanism which contributes to the expansion of new blood vessels within a tumor involves incorporation of bone marrow derived, Endothelial Progenitor Cells (EPC) into capillaries, although it is not yet clear how this affects the entire process of angiogenesis. It has been demonstrated that increased serum VEGF promotes and enhances the differentiation of bone marrow stem cell lines towards the endothelial phenotype (Takahashi et al., 1999; Gill et al., 2001). Furthermore, it has also been shown that increased production of VEGF by tumor cells favors the mobilization of these progenitor cells from the bone marrow to the peripheral circulation and increases their recruitment into tumor vasculature (Asahara et al., 1999; Hattori et al., 2000). Even hypoxia, which is often present in areas within a tumor could increase the mobilization of EPCs from the bone marrow and thus contribute to the process of neoangiogenesis (Takahashi et al., 1999).

In veterinary medicine in the last decade, several studies have been designed to demonstrate increased proangiogenic factors during tumor expression.

Immunohistochemistry or real-Time Polymerase Chain Reaction (RT-PCR) have been used to observe expression of VEGF and/or their receptors and/or MMP in canine breast cancer (Queiroga et al., 2011; Al-Dissi et al., 2010; Qiu et al., 2008a; 2008b; Restucci et al., 2002), mast cell tumors (Giantin et al., 2012; Patruno et al., 2009; Rebuzzi et al., 2007), hemangiosarcoma (Yonemaru et al., 2006), intracranial tumors of various origins (Rossmeisl et al., 2007; Platt et al., 2006; Dickinson et al., 2008) nasal epithelial neoplasia (Shiomitsu et al., 2009), lymphomas (Wolfesberger et al., 2007; 2008; 2012), melanoma (Taylor et al., 2007) meningiomas (Matiasek et al., 2009), squamous cell carcinomas (Al-Dissi et al., 2007; Maiolino et al., 2000) and soft tissue sarcomas (Queiroz et al., 2010).

Other studies have tried to correlate this expression with Microvascular Density (MVD) (Queiroz et al., 2010; Wolfesberger et al., 2008; 2012), with expression of COX-2 and MVD (Queiroga et al., 2011) and with other factors (Yonemaru et al., 2006; Qiu et al., 2008b; Matiasek et al., 2009).

Other surveys have focused on observation of blood concentrations of VEGF and/or MMP in various malignancies (Troy et al., 2006; Wergin and Kaser-Hotz, 2004; Marchetti et al., 2012) or in well-defined tumors such as lymphoma (Aresu et al., 2012; Gentilini et al., 2005; Zizzo et al., 2010), intracranial cancer (Rossmeisl et al., 2007), melanoma (Taylor et al., 2007), hemangiosarcoma (Clifford et al., 2001), breast cancer (Kato et al., 2007), osteosarcoma (Thamm et al., 2008) and soft tissue sarcoma (Queiroz et al., 2012).

\subsection{The Metronomic Chemotherapy Approach: From Humans to Dogs}

In veterinary oncology where the highest priority is maintaining patient quality of life, it is important that new chemotherapy strategies aim to minimize side effects, so treatment is more attractive for owners as well as their pets. 
Browder et al. (2000) and Klement et al. (2000) published two pioneering works demonstrating the effectiveness of some anti-angiogenic drugs administered continuously at low doses in subcutaneous tumors in mice chemoresistant for the same drugs. This mode of administration was termed "metronomic" (Hanahan et al., 2000). While preclinical studies have shown that the release of endothelial progenitor cells from the bone marrow is stimulated by high-dose chemotherapy but suppressed by low-doses (Munoz et al., 2006; Hanahan et al., 2000; Mancuso et al., 2006; Bertolini et al., 2003), others have shown that the cytotoxic agent induced damage to the tumor vasculature can be repaired in the interval between two cycles of chemotherapy (Giovannini et al., 2010). The main purpose of metronomic chemotherapy is to eliminate or at least minimize this time interval thus limiting the extent of cell repair, further cell replication and alteration of the tumor microenvironment.

It has been observed that metronomic chemotherapy does not have a significant direct cytotoxic effect against tumor cells but rather is able to modify the tumor microenvironment. One of its prime effects is to delay or render ineffective the tumour's capacity to generate new blood vessels for the tumor stroma. It does this in various ways (Gonzalez-Billalabeitia et al., 2009; Miller et al., 2001; Pasquier et al., 2007; Laquente et al., 2007): (i) a selective induction of apoptosis and inhibition of proliferation and migration of activated endothelial cells (Bocci et al., 2002; Blansfield et al., 2008; Pasquier et al., 2010); (ii) modulating inhibitory (e.g., thrombospondin1) and stimulatory factors of angiogenesis (Bocci et al., 2003; Pasquier et al., 2010; Park et al., 2010; Damber et al., 2006); (iii) inhibition of endothelial cell microtubules in vitro (Kerbel and Kamen, 2004); (iv) targeting Circulating Endothelial Progenitor Cells (CEPC) (Kerbel and Kamen, 2004; Mutsaers, 2007); (v) modulating the cell cycle through the upregulation of caveolin-1 and the downregulation of cyclin D1 (Bocci et al., 2012); (vi) reducing Treg cells that inhibit cell-mediated immunity against self cells (Burton et al., 2011) and stimulating the action of Dendritic cells (Tanaka et al., 2009a; 2009b).

These preclinical studies have led onto a series of clinical experimental trials in different types of cancer such as human breast cancer (Colleoni et al., 2002; 2006; Wong et al., 2010; Gonzalez-Billalabeitia et al., 2009; Bottini et al., 2006; Orlando et al., 2006; Dellapasqua et al., 2008; Garcia-Saenz et al., 2008), ovarian cancer (JuradoGarcia et al., 2008; Garcia et al., 2008), prostate cancer (Glode, 2003; Lord et al., 2007; Fontana et al., 2009; 2010a; 2010b), cancer effecting the kidney (Krzyzanowska et al., 2007; Bellmunt et al., 2010), colon (Allegrini et al., 2008; 2012; Nannini et al., 2009), lung (Kato et al., 2004), adrenal medulla (Wortmann et al., 2010), nerves (Kong et al., 2006; Reardon et al., 2009; Stupp et al., 2005), in some lymphomas (Buckstein et al., 2006), melanoma (Bhatt et al., 2010) and others (Weerdt et al., 2001; Young et al., 2006; Steinbild et al., 2007; Briasoulis et al., 2009; Vogt et al., 2003).

Several drugs or their analogues were used for metronomic chemotherapy clinical schedules including cyclophosphamide (Penel et al., 2012), methotrexate (Colleoni et al., 2002; 2006; Wong et al., 2010; Gonzalez-Billalabeitia et al., 2009; Orlando et al., 2006; Garcia-Saenz et al., 2008), capecitabine (Dellapasqua et al., 2008), vinorelbine (Saloustros et al., 2011), irinotecan (Allegrini et al., 2008) and UFT (Allegrini et al., 2012).

Metronomic chemotherapy has been shown to have an important stabilizing effect on cancer (including chemotherapy-resistant disease) conferring prolonged clinical benefit and to have positive effects on the quality of life of patients with various types of cancer, without highgrade toxicity (Nelius et al., 2011). Moreover, low cost (Bocci et al., 2005) and oral administration (which reduces the need for hospitalization and enables patients to stay at home longer) are key characteristics of this schedule, offering important advantages in frail subgroups of patients (e.g., old patients) for whom new therapeutic options are greatly needed (Fontana et al., 2010b).

Based on the above mentioned studies, metronomic chemotherapy is increasingly being considered by veterinary oncologist as an anticancer therapeutic strategy. The first report of a metronomic chemotherapy protocol was presented as an abstract at the annual conference of the Veterinary Cancer Society a decade ago (Mutsaers, 2009). In that work, different types of tumors were treated with cyclophosphamide at $25 \mathrm{mg}$ $\mathrm{m}^{-2}$ in combination with piroxicam $0.3 \mathrm{mg} \mathrm{kg}^{-1}$ daily. An objective response was achieved in two dogs after one month of therapy.

The first full paper was not published for another 6 years (Lana et al., 2007). It compared the outcome of nine dogs with splenic hemangiosarcoma treated with a traditional doxorubicin protocol dose-intense singleagent chemotherapy and nine dogs with the same disease treated with metronomic chemotherapy. The protocol consisted of piroxicam $0.3 \mathrm{mg} \mathrm{kg}^{-1}$ in combination with cyclophosphamide or etoposide at 12.5 to $25 \mathrm{mg} \mathrm{m}^{-2}$ to $50 \mathrm{mg} \mathrm{m} \mathrm{m}^{-2}$ administered daily for six months. Surprisingly, the median survival time and to an even larger extent, the disease-free interval proved better with 
the metronomic protocol than with the traditional one, resulting in 178 days as compared to 133 and 178 days versus 126 respectively (Lana et al., 2007).

However, this study provided important information on toxicity. Toxicity did not exceed grade 2 according to the VCOG (VCOG, 2004) with the metronomic chemotherapy while gastroenteric toxicity was observed at grade 3 and 4 with doxorubicin. However, hemorrhagic cystitis was reported in two patients treated with cyclophosphamide.

A year later Elmslie et al. (2008) published a study of 85 dogs. Participating dogs had had a soft tissue sarcoma that had been incompletely excised, one group was treated with metronomic chemotherapy (30) the other group received no treatment (55). The protocol consisted of cyclophosphamide at $10 \mathrm{mg} \mathrm{m}^{-2}$ combined with piroxicam $0.3 \mathrm{mg} \mathrm{kg}^{-1}$ daily or on alternate days. The treated group had a disease-free interval almost double that of the untreated group (410 versus 211 days). Toxicity was reported as mild, about $40 \%$ of animals were reported as having grade 1 or 2 signs and only 1 subject developed hemorrhagic cystitis (grade 4).

The next paper on metronomic treatment was published in early 2012. Fifteen dogs with various tumors with distant metastases were treated with metronomic chemotherapy as first line treatment (Marchetti et al., 2012). The protocol consisted of daily administration of cyclophosphamide, $25 \mathrm{mg} \mathrm{m}^{-2}$ and

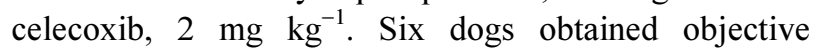
responses, including one complete remission. The average survival time was more than three months and toxicity almost absent. In this study, VEGF was measured before treatment and dogs who responded to the protocol showed a statistically significant lower blood concentration if compared to dogs who didn't respond.

In the same year, a study on 81 dogs with inoperable tumors, or tumors that had been incompletely removed or were chemoresistant with macroscopic evidence of distant metastases, was published (Tripp et al., 2011). These dogs were treated with lomustine at $2.84 \mathrm{mg} \mathrm{m}^{-2}$ daily given orally for an average of 98 days. In almost half the cases, lomustine was used in conjunction with an anti-inflammatory drug, in 29 dogs an NSAID was used. Results obtained using this protocol were comparable to those obtained by Marchetti et al. (2012), with a response rate of $36 \%$. The non progression of the disease, observed in approximately $30 \%$ of cases, had a duration of about 137 days. Even the toxicity evaluation aligns with the studies cited above with mild gastrointestinal symptoms occurring in about a quarter of patients. In about $21 \%$ of cases there was an increase in
ALT, probably because of liver toxicity induced by lomustine. Finally, thrombocytopenia was found in about one-fifth of the cases, however this was rarely higher than second degree toxicity. This predominantly occurred in patients with end-stage cancer, probably due to a cumulative toxicity.

A prospective study was designed to observe the efficacy of metronomic dosing of cyclophosphamide to reduce the number of circulating Treg cells and tumor Microvessel Density (MVD, microvessel density) in dogs with Soft Tissue Sarcoma (STS Soft Tissue sarcoma). $11 \mathrm{dogs}$ were treated daily with $12.5 \mathrm{mg} \mathrm{m}^{-2}$ ( 5 cases) or $15 \mathrm{mg} \mathrm{m}^{-2}$ (6 cases) of cyclophosphamide per os while 21 healthy dogs were used as a control. The results showed significant efficacy in reducing the number of Treg lymphocytes circulating at both doses, while only the group treated with $15 \mathrm{mg} \mathrm{m}^{-2}$ showed a reduction in MVD (Burton et al., 2011).

In a recent study, chlorambucil was administered at a dose of $4 \mathrm{mg} \mathrm{m}^{-2}$ daily in dogs with spontaneous cancer (Leach et al., 2012). Of 36 cases, 58\% recorded an objective response, with an overall mean survival time of 153 days. As in other trials, the observed toxicity did not exceed grade 2 .

In a prospective study (Mitchell et al., 2012), 15 dogs with advanced malignancies were subjected to an experimental chemotherapy protocol that included a combination of metronomic cyclophosphamide $(15 \mathrm{mg}$ $\mathrm{m}^{-2}$ ) and toceranib, a tyrosine kinase inhibitor recently approved for the treatment of canine mast cell tumors (London et al., 2003; 2009). The purpose of the study was not to observe the clinical response to treatment but rather to observe change in the number of circulating Treg cells and blood concentrations of interferon gamma (IFN- $\gamma$ ). The period of follow-up monitoring was short at 8 weeks, during this period 6 objective responses occurred, defined as stable disease and gastrointestinal and hematological toxicity no higher than grade 2 .

In veterinary medicine, metronomic chemotherapy has several advantages compared to regime intense chemotherapy, especially in the context of veterinary oncology. There is minimal impact on the animal, cost is low and administration simple. Chemotherapy in low doses can be administered at home with minimal stress on the patient and minimal impact on the logistic organization of the owner. As cost of treatment is influential in choosing a therapeutic option, this type of chemotherapy, as compared with dose-intense protocols, has an unquestionable advantage. It has a low cost, approximately $1 / 10$ th of the cost of an intense scheme therapy. 
Last, but not least, metronomic therapies have been shown to infrequently cause toxicity in veterinary patients (Lana et al., 2007; Tripp et al., 2011; Marchetti et al., 2012; Leach et al., 2012), except for an isolated case of hemorrhagic cystitis (Elmslie et al., 2008). This contributes to the cost-effectiveness of such a protocol as it rarely requires the use of medications to treat the side effects and it results in much less time in hospital, both events that contribute to the higher overall costs of a dose-intense protocol.

Given the encouraging results from various trials (Elmslie et al., 2008; Marchetti et al., 2012; Tripp et al., 2011), metronomic chemotherapy is offered as the treatment of choice for all patients with malignant tumors where owners are reluctant to embark on an aggressive therapy protocol, including surgery with a high American Society of Anesthesiologists ASA score.

It is also indicated in all patients with organ failure such as hepatic or renal insufficiency, in which the toxicity of chemotherapy may be fatal. In summary, metronomic chemotherapy achieves the main goals of veterinary oncology: Good quality of life of the patient, with an affordable cost/benefit ratio. It can be also offered as an alternative to dose intense chemotherapy in cases where the owners are not able to manage any side effects or where simple precautions required for elimination of drugs cannot be complied with.

Metronomic therapy could also present an attractive option in patients with an aggressive nature that would require sedation for each parenteral administration.

Finally, it is certainly proposed as being at the forefront of palliative care for patients at an advanced clinical stage, given that the objective in these cases is usually to stabilize disease with the least possible impact on the individual.

\subsection{Candidate Drugs for Combinations with Metronomic Chemotherapy in Dogs}

In human therapy in recent years, considerable interest has developed in drugs that could be easily used in combination with metronomic chemotherapy, such as Nonsteroidal Anti-Inflammatory Drugs (NSAIDs) (Giorgi et al., 2012) and tyrosine kinase inhibitors (Kerbel, 2012).

The COX enzymes are mainly responsible for the conversion of arachidonic acid to Prostaglandins (PG). PGs have been shown to play a significant role in many disease processes including oncogenesis (Dore, 2011). Three isoforms of COX are known: COX-1, this is constitutive for the majority of cells and tissues and participates in the maintenance of homeostasis (Vane, 1971). COX-3 has been identified in the dog but its role is unknown (Chandrasekharan et al., 2002). COX-2 is normally present in a limited number of tissues, it is mainly expressed in pathological states such as in inflammatory reactions and in tumors upon stimulation by inflammatory mediators such as Interleukin-1 (IL-1), TNF-1 and lipopolysaccharides (Herschman, 2004; Masferrer et al., 1990). In humans, the contribution of PG to tumorigenesis (Greenhough et al., 2009) has been also described. PGE2 has been shown to exert its action by binding to a specific class of receptors on the cell surface, called EP. Through this binding, it influences a series of intracellular events that lead to tumor development. These include induction of cell proliferation and increased cell survival via inhibition of mechanisms of apoptosis. PGs also promote angiogenesis through the production of growth factors such as VEGF and bFGF. Cumulatively, this leads to increased invasion and metastatic capacity and suppression of the immune response (Greenhough et al., 2009; Gupta et al., 2007; Harris et al., 2002; Tsuji et al., 1998).

In dogs, several studies have shown increased expression of COX-2 in tumor tissues such as breast cancer (Souza et al., 2009; Dore et al., 2003; Heller et al., 2005; Queiroga et al., 2005; 2007), prostate cancer (L'Eplattenier et al., 2007; Mohammed et al., 2004; Sorenmo et al., 2004; Tremblay et al., 1999), transitional cell carcinoma (Khan et al., 2000; Knottenbelt et al., 2006; Lee et al., 2007), squamous cell carcinoma (Mohammed et al., 2004; Almeida et al., 2001) and many other forms of tumor (Boria et al., 2004; Borzacchiello et al., 2004; 2007; Impellizeri and Esplin, 2008; Khan et al., 2001; Kleiter et al., 2004; Mohammed et al., 2004; Mullins et al., 2004; Rossmeisl et al., 2009). NSAIDs have demonstrated antitumor efficacy in vitro (Brunelle et al., 2006; Pronovost et al., 2004; Wolfesberger et al., 2006) and they have been used in some clinical trials initially as a single agent (Schmidt et al., 2001; Knapp et al., 1994; Mohammed et al., 2002; Mutsaers et al., 2005; Sorenmo et al., 2004; Souza et al., 2009), revealing a response rate ranging from 17 to $33 \%$. This rate increased to $47-83 \%$ if the objective was stable disease. These drugs were used in intensive chemotherapy regimens for oral squamous cell carcinomas and melanomas with a response rate of $25 \%$ (Boria et al., 2004).

Another class of drugs subject to much interest in the veterinary field in the last decade is Tyrosine Kinase Inhibitors (TKI). 
The Tyrosine Kinase Receptors (TKR) are proteins that generally occur as monomers on the cell surface. They play a key role in the normal cellular signal transduction, regulating growth and cell differentiation. TKR interacts with Adenosine Triphosphate (ATP) by adding a phosphate group to its residues ("autophosphorylation") and onto other molecules to generate intracellular signals that influence proliferation and cell survival (London, 2004). This process generally begins in response to external signals generated by growth factors or other stimuli that trigger the cascade of tyrosine phosphorylation.

The TKR are aberrant in many tumors in dogs and humans. The anomalies include overexpression, activating mutations and autocrine activation through the co-expression of the receptor and the growth factor (Shchemelinin et al., 2006). This causes continuous stimulation of cellular signals that induce altered proliferation and cell survival, even in the absence of adequate stimulation (London, 2009).

The most studied TKR is certainly TKI or CD-117 in the dog. It is often mutated in mast cell tumors (Pryer et al., 2003) and Gastrointestinal Stromal Tumors (GIST) (Frost et al., 2003) in the dog.

Several other receptors such as VEGFR, PDGFR and FGFR (Dubreuil et al., 2009) are included in the TKR family.

The TKI drugs are small molecules capable of binding selectively to and inhibiting the RTKs. These act by reversibly or irreversibly blocking binding sites for ATP on kinase enzymes (Wanebo et al., 2006; Wakeling, 2005; Shchemelinin et al., 2006); in the absence of ATP binding, the kinase cannot work.

In veterinary medicine, few studies have been conducted investigating the efficacy of these anticancer drugs thus far. The use of imatinib (Isotani et al., 2008; Marconato et al., 2008), masitinib (Hahn et al., 2008) and toceranib (Pryer et al., 2003; London et al., 2009) for the treatment of mastocytomas has been tested in the dog, mainly investigating its inhibition of KIT. However toceranib, which has demonstrated a wider range of target TKs, has also been used in the treatment of other tumors, such as lymphoma, breast cancer, carcinoma of the bladder transitional cell, soft tissue sarcoma, melanoma, osteosarcoma, hemangiosarcoma, squamous cell carcinoma of the tongue, multiple myeloma, bronchial carcinoma, sebaceous carcinoma and anaplastic carcinoma (London et al., 2003).

Due to this property, but also others, toceranib is able to inhibit receptors in addition to KIT TK, such as VEGFR, PDGFR and Flt-3. That has sparked interest in the use of TKIs as an antiangiogenic agent.
Other studies have also shown an immunomodulatory effect for this class of drugs. In particular, a recent study of 15 dogs affected by cancer, demonstrated toceranib's ability to reduce the number of circulating Treg lymphocytes, thus suggesting an additional antitumor action for this molecule (Mitchell et al., 2012). This effect was already described in humans with sunitinib (Finke et al., 2008). Mitchell et al. (2012) tested toceranib as a single agent and subsequently it was combined with cyclophosphamide in a metronomic regime. No significant difference was observed in the absolute number of Treg lymphocytes before and after drug treatment. It was speculated that a synergistic effect in maintaining low levels of circulating Treg took place.

Another drug of current interest to the scientific community due to its anti-angiogenic properties in canine tumors is thalidomide. This drug has an immunomodulatory and antiangiogenetic effect (Kenyon et al., 1997). Its antiangiogenic effect on canine tumors has been demonstrated using canine osteosarcoma cells transplanted into athymic nude mice (Farese et al., 2004).

To our knowledge, to date the only clinical study on the efficacy of thalidomide in veterinary oncology has involved an unresectable case of head and neck squamous cell carcinoma in a cat (Marconato et al., 2012). Several unpublished studies on thalidomide are ongoing with interesting findings (Pierini, personal communication).

\section{CONCLUSION}

Cancer in dogs shares many features with human cancer, including histological appearance, tumor genetics, molecular targets, biological behavior and response to conventional therapies, so much so that the dog is considered a good model of human pathology (Paoloni and Khanna, 2007; Giorgi, 2012). The initiation and tumor progression in both species is influenced by similar factors including age, nutrition, sex, reproductive status and environmental exposure; for the latter in particular, the $\operatorname{dog}$ is considered a sentinel of environmental exposure because of its shorter life span (Bukowski et al., 1998; Marconato et al., 2009; Bettini et al., 2010). Furthermore, most, if not all, of the cancer associated genetic alterations that influence cancer progression in humans have been identified in canine cancer. Thus, the genome of the dog and human are similar enough to suggest that information learnt 
about one species can be extrapolated and applied to the other (Ostrander et al., 2006; Lindblad-Toh et al., 2005). Many of the chemotherapy protocols used in veterinary medicine are based upon protocols used in human patients and they have similar treatment outcomes. For this reason, dogs serve as unique animal models for some human tumors, because they adequately mimic many of the features that define cancer in humans, including long periods of latency, genomic instability and an intact immune system (Gordon et al., 2009).

Thus, the metronomic chemotherapy experience in dogs could reveal innovative and unexplored schedules for humans. Veterinary oncology cases treated with metronomic schedules represent the unique opportunity to ethically investigate novel drugs or combination treatments that may be highly translatable to the human community.

\section{ACKNOWLEDGEMENT}

This study has been supported, in part, by AIRC (Associazione Italiana per la Ricerca sul Cancro) to Guido Bocci.

\section{REFERENCES}

Al-Dissi, A.N., D.M. Haines, B. Singh and B.A. Kidney, 2007. Immunohistochemical expression of vascular endothelial growth factor and vascular endothelial growth factor receptor associated with tumor cell proliferation in canine cutaneous squamous cell carcinomas and trichoepitheliomas. Vet. Pathol., 44: 823-830. PMID: 18039895

Al-Dissi, A.N., D.M. Haines, B. Singh and B.A. Kidney, 2010. Immunohistochemical expression of vascular endothelial growth factor and vascular endothelial growth factor receptor-2 in canine simple mammary gland adenocarcinomas. Can. Vet. J., 51: 11091114. PMID: 21197202

Allegrini, G., A. Falcone, A. Fioravanti, M.T. Barletta and P. Orlandi et al., 2008. A pharmacokinetic and pharmacodynamic study on metronomic irinotecan in metastatic colorectal cancer patients. Br. J. Cancer, 98: 1312-1319. PMID: 18362940

Allegrini, G., T.D. Desidero, M.T. Barletta, A. Fioravanti and P. Orlandi et al., 2012. Clinical, pharmacokinetic and pharmacodynamic evaluations of metronomic UFT and cyclophosphamide plus celecoxib in patients with advanced refractory gastrointestinal cancers. Angiogenesis, 15: 275-286. PMID: 22382585
Almeida, E.M.P.D., C. Piche, J. Sirois and M. Dore, 2001. Expression of cyclo-oxygenase-2 in naturally occurring squamous cell carcinomas in dogs. J. Histochem. Cytochem., 49: 867-875. PMID: 11410611

Aresu, L., A. Arico, S. Comazzi, M.E. Gelain and F. Riondato et al., 2012. VEGF and MMP-9: Biomarkers for canine lymphoma. Vet. Comp. Oncol. PMID: 22489798

Asahara, T., T. Takahashi, H. Masuda, C. Kalka and D. Chen et al., 1999. VEGF contributes to postnatal neovascularization by mobilizing bone marrowderived endothelial progenitor cells. EMBO J., 18: 3964-3972. PMID: 10406801

Bellmunt, J., J.M. Trigo, E. Calvo, J. Carles and J.L. Perez-Gracia et al., 2010. Activity of a multitargeted chemo-switch regimen (sorafenib, gemcitabine and metronomic capecitabine) in metastatic renal-cell carcinoma: A phase 2 study (SOGUG-02-06). Lancet Onc., 11: 350-357. PMID: 20163987

Bertolini, F., S. Paul, P. Mancuso, S. Monestiroli and A. Gobbi et al., 2003. Maximum tolerable dose and low-dose metronomic chemotherapy have opposite effects on the mobilization and viability of circulating endothelial progenitor cells. Cancer Res., 63: 4342-4346. PMID: 12907602

Bettini, G., M. Morini, L. Marconato, P.S. Marcao and E. Zini, 2010. Association between environmental dust exposure and lung cancer in dogs. Vet. J., 186: 364-369. PMID: 20044284

Bhatt, R.S., J. Merchan, R. Parker, H.K. Wu and L. Zhang et al., 2010. A phase 2 pilot trial of low-dose, continuous infusion, or "metronomic" paclitaxel and oral celecoxib in patients with metastatic melanoma. Cancer, 116: 1751-1756. PMID: 20120033

Blansfield, J.A., D. Caragacianu, H.A. Alexander, M.A. Tangrea and S.Y. Morita et al., 2008. Combining agents that target the tumor microenvironment improves the efficacy of anticancer therapy. Clin. Cancer Res., 14: 270-280. PMID: 18172279

Bocci, G., A. Fioravanti, P. Orlandi, T.D. Desidero and G. Natale et al., 2012. Metronomic ceramide analogs inhibit angiogenesis in pancreatic cancer through up-regulation of caveolin-1 and thrombospondin-1 and down-regulation of cyclin D1. Neoplasia, 14: 833-845. PMID: 2301941

Bocci, G., G. Francia, S. Man, J. Lawler and R.S. Kerbel, 2003. Thrombospondin 1, a mediator of the antiangiogenic effects of low-dose metronomic chemotherapy. Proc. Natl. Acad. Sci. USA., 100: 12917-12922. PMID: 14561896 
Bocci, G., K.C. Nicolaou and R.S. Kerbel, 2002. Protracted low-dose effects on human endothelial cell proliferation and survival in vitro reveal a selective antiangiogenic window for various chemotherapeutic drugs. Cancer Res., 62: 69386943. PMID: 12460910

Bocci, G., M. Tuccori, U. Emmenegger, V. Liguori and A. Falcone et al., 2005. Cyclophosphamidemethotrexate 'metronomic' chemotherapy for the palliative treatment of metastatic breast cancer. A comparative pharmacoeconomic evaluation. Ann. Oncol., 16: 1243-1252. PMID: 15905308

Boria, P.A., D.J. Murry, P.F. Bennett, N.W. Glickman and P.W. Snyder et al., 2004. Evaluation of cisplatin combined with piroxicam for the treatment of oral malignant melanoma and oral squamous cell carcinoma in dogs. J. Am. Vet. Assoc., 224: 388394. PMID: 14765798

Borzacchiello, G., O. Paciello and S. Papparella, 2004. Expression of cyclooxygenase- 1 and -2 in canine nasal carcinomas. J. Comp. Pathol., 131: 70-76. PMID: 15144801

Borzacchiello, G., V. Russo and M. Russo, 2007. Immunohistochemical expression of cyclooxygenase-2 in canine ovarian carcinomas. J. Vet. Med. A. Physiol. Pathol. Clin. Med., 54: 247249. PMID: 17523957

Bottini, A., D. Generali, M.P. Brizzi, S.B. Fox and A. Bersiga et al., 2006. Randomized phase II trial of letrozole and letrozole plus low-dose metronomic oral cyclophosphamide as primary systemic treatment in elderly breast cancer patients. J. Clin. Oncol., 24: 3623-3628. PMID: 16877730

Briasoulis, E., P. Pappas, C. Puozzo, C. Tolis and G. Fountzilas et al., 2009. Dose-ranging study of metronomic oral vinorelbine in patients with advanced refractory cancer. Clin. Cancer Res., 15: 6454-6461. PMID: 19808873

Browder, T., C.E. Butterfield, B.M. Kraling, B. Shi and B. Marshall et al., 2000. Antiangiogenic scheduling of chemotherapy improves efficacy against experimental drug-resistant cancer. Cancer Res., 60: 1878-1886. PMID: 10766175

Brunelle, M., E.A. Sartin, L.G. Wolfe, J. Sirois and M. Dore, 2006. Cyclooxygenase-2 expression in normal and neoplastic canine mammary cell lines. Vet. Pathol., 43: 656-666. PMID: 16966442
Buckstein, R., R.S. Kerbel, Y. Shaked, R. Nayar and C. Foden et al., 2006. High-dose celecoxib and metronomic "low-dose" cyclophosphamide is an effective and safe therapy in patients with relapsed and refractory aggressive histology non-Hodgkin's lymphoma. Clin. Cancer Res., 12: 5190-5198. PMID: 16951238

Bukowski, J.A., D. Wartenberg and M. Goldschmidt, 1998. Environmental causes for sinonasal cancers in pet dogs and their usefulness as sentinels of indoor cancer risk. J. Toxicol. Environ. Health A., 54: 579591. PMID: 9726781

Burton, J.H., L. Mitchell, D.H. Thamm, S.W. Dow and B.J. Biller, 2011. Low-dose cyclophosphamide selectively decreases regulatory $\mathrm{T}$ cells and inhibits angiogenesis in dogs with soft tissue sarcoma. J. Vet. Intern. Med., 25: 920-926. PMID: 21736624

Chandrasekharan, N.V., H. Dai, K.L. Roos, N.K. Evanson and J. Tomsik et al., 2002. COX-3, a cyclooxygenase-1 variant inhibited by acetaminophen and other analgesic/antipyretic drugs: Cloning, structure and expression. Proc. Natl. Acad. Sci. USA., 99: 13926-13931. PMID: 12242329

Clifford, C.A., D. Hughes, M.W. Beal, A.J. Mackin and C.J. Henry et al., 2001. Plasma vascular endothelial growth factor concentrations in healthy dogs and dogs with hemangiosarcoma. J. Vet. Intern. Med., 15: 131-135. PMID: 11300596

Colleoni, M., A. Rocca, M.T. Sandri, L. Zorzino and G. Masci et al., 2002. Low-dose oral methotrexate and cyclophosphamide in metastatic breast cancer: Antitumor activity and correlation with vascular endothelial growth factor levels. Ann. Oncol., 13: 73-80. PMID: 11863115

Colleoni, M., L. Orlando, G. Sanna, A. Rocca and P. Maisonneuve et al., 2006. Metronomic low-dose oral cyclophosphamide and methotrexate plus or minus thalidomide in metastatic breast cancer: Antitumor activity and biological effects. Ann. Oncol., 17: 232-238. PMID: 16322118

Damber, J.E., C. Vallbo, P. Albertsson, B. Lennernas and K. Norrby, 2006. The anti-tumour effect of lowdose continuous chemotherapy may partly be mediated by thrombospondin. Cancer Chemother. Pharmacol., 58: 354-360. PMID: 16333676

Dellapasqua, S., F. Bertolini, V. Bagnardi, E. Campagnoli and E. Scarano et al., 2008. Metronomic cyclophosphamide and capecitabine combined with bevacizumab in advanced breast cancer. J. Clin. Oncol., 26: 4899-4905. PMID: 18794539 
Dickinson, P.J., B.K. Sturges, R.J. Higgins, B.N. Roberts and C.M. Leutenegger et al., 2008. Vascular endothelial growth factor mRNA expression and peritumoral edema in canine primary central nervous system tumors. Vet. Pathol., 45: 131-139. PMID: 18424825

Dore, M., 2011. Cyclooxygenase-2 expression in animal cancers. Vet. Pathol., 48: 254-265. PMID: 20876365

Dore, M., I. Lanthier and J. Sirois, 2003. Cyclooxygenase-2 expression in canine mammary tumors. Vet. Pathol., 40: 207-212. PMID: 12637762

Dubreuil, P., S. Letard, M. Ciufolini, L. Gros and M. Humbert et al., 2009. Masitinib (AB1010), a potent and selective tyrosine kinase inhibitor targeting KIT. PLoS One., 4: e7258-e7258. PMID: 19789626

Elmslie, R.E., P. Glawe and S.W. Dow, 2008. Metronomic therapy with cyclophosphamide and piroxicam effectively delays tumor recurrence in dogs with incompletely resected soft tissue sarcomas. J. Vet. Intern. Med., 22: 1373-1379. PMID: 18976288

Farese, J.P., L.E. Fox, C.J. Detrisac, J.M.V. Gilder and S.L. Roberts et al., 2004. Effect of thalidomide on growth and metastasis of canine osteosarcoma cells after xenotransplantation in athymic mice. Am. J. Vet. Res., 65: 659-664. PMID: 15141888

Ferrara, N., H.P. Gerber and J. LeCouter, 2003. The biology of VEGF and its receptors. Nat. Med., 9: 669-676. PMID: 12778165

Finke, J.H., B. Rini, J. Ireland, P. Rayman and A. Richmond et al., 2008. Sunitinib reverses type-1 immune suppression and decreases T-regulatory cells in renal cell carcinoma patients. Clin. Cancer Res., 14: 6674-6682. PMID: 18927310

Folkman, J., 1971. Tumor angiogenesis: Therapeutic implications. N. Engl. J. Med., 285: 1182-1186. PMID: 4938153

Fontana, A., A. Falcone, L. Derosa, T.D. Desidero and R. Danesi et al., 2010b. Metronomic chemotherapy for metastatic prostate cancer: A 'young' concept for old patients? Drugs Aging., 27: 689-696. PMID: 20809660

Fontana, A., G. Bocci, L. Galli, M. D’Arcangelo, L. Derosa et al., 2010a. Metronomic cyclophosphamide in elderly patients with advanced, castration-resistant prostate cancer. J. Am. Geriatr. Soc., 58: 986-988. PMID: 20722827
Fontana, A., L. Galli, A. Fioravanti, P. Orlandi and C. Galli et al., 2009. Clinical and pharmacodynamic evaluation of metronomic cyclophosphamide, celecoxib and dexamethasone in advanced hormonerefractory prostate cancer. Clin. Cancer Res., 15: 4954-4962. PMID: 19622584

Frost, D., J. Lasota and M. Miettinen, 2003. Gastrointestinal stromal tumors and leiomyomas in the dog: A histopathologic, immunohistochemical and molecular genetic study of 50 cases. Vet. Pathol., 40: 42-54. PMID: 12627712

Garcia, A.A., H. Hirte, G. Fleming, D. Yang and D.D. Tsao-Wei et al., 2008. Phase II clinical trial of bevacizumab and low-dose metronomic oral cyclophosphamide in recurrent ovarian cancer: A trial of the California, Chicago and Princess Margaret Hospital phase II consortia. J. Clin. Oncol., 26: 76-82. PMID: 18165643

Garcia-Saenz, J.A., M. Martin, A. Calles, C. Bueno and L. Rodriguez et al., 2008. Bevacizumab in combination with metronomic chemotherapy in patients with anthracycline- and taxane-refractory breast cancer. J. Chemother., 20: 632-639. PMID: 19028628

Gentilini, F., C. Calzolari, M.E. Turba, C. Agnoli and D. Fava et al., 2005. Prognostic value of serum Vascular Endothelial Growth Factor (VEGF) and plasma activity of Matrix Metalloproteinase (MMP) 2 and 9 in lymphoma-affected dogs. Leuk. Res., 29: 1263-1269. PMID: 15893373

Giantin, M., L. Aresu, S. Benali, A. Arico and E.M. Morello et al., 2012. Expression of matrix metalloproteinases, tissue inhibitors of metalloproteinases and vascular endothelial growth factor in canine mast cell tumours. J. Comp. Pathol., 147: 419-429. PMID: 22520817

Gill, M., S. Dias, K. Hattori, M. L. Rivera and D. Hicklin et al., 2001. Vascular trauma induces rapid but transient mobilization of VEGFR2(+) AC133(+) endothelial precursor cells. Circ. Res., 88: 167-174. PMID: 11157668

Giorgi, M., 2012. Veterinary pharmacology: is it still pharmacology's cinderella? Clin. Exp. Pharmacol., 2: 103-103. DOI: 10.4172/2161-1459.1000e103

Giorgi, M., G. Saccomanni, S.D. Carlo, C. Manera and E. Lavy, 2012. Pharmacokinetics of intravenous and intramuscular parecoxib in healthy beagles. Vet. J., 193: 246-250. PMID: 22130459

Giovannini, M., D. Aldrighetti, P. Zucchinelli, C. Belli and E. Villa, 2010. Antiangiogenic strategies in breast cancer management. Crit. Rev. Oncol. Hematol., 76: 13-35. PMID: 20702105 
Glode, L.M., A. Barqawi, F. Crighton, E.D. Crawford and R. Kerbel, 2003. Metronomic therapy with cyclophosphamide and dexamethasone for prostate carcinoma. Cancer, 98: 1643-1648. PMID: 14534880

Gonzalez-Billalabeitia, E., J. Calzas, D. Castellano, C. Mendiola and S. Bezares et al., 2009. Long-term follow-up of an anthracycline-containing metronomic chemotherapy schedule in advanced breast cancer. Breast J., 15: 551-553. PMID: 19671111

Gordon, I., M. Paoloni, C. Mazcko and C. Khanna, 2009. The Comparative Oncology Trials Consortium: Using spontaneously occurring cancers in dogs to inform the cancer drug development pathway. PLoS Med., 6: e1000161-e1000161. PMID: 19823573

Greenhough, A., H.J. Smartt, A.E. Moore, H.R. Roberts and A.C. Williams et al., 2009. The COX-2/PGE2 pathway: Key roles in the hallmarks of cancer and adaptation to the tumour microenvironment. Carcinogenesis, 30: 377-386. PMID: 19136477

Gupta, G.P., D.X. Nguyen, A.C. Chiang, P.D. Bos and J.Y. Kim et al., 2007. Mediators of vascular remodelling co-opted for sequential steps in lung metastasis. Nature, 446: 765-770. PMID: 17429393

Hahn, K.A., G. Oglivie, T. Rusk, P. Devauchelle and A. Leblanc et al., 2008. Masitinib is safe and effective for the treatment of canine mast cell tumors. J. Vet. Intern. Med., 22: 1301-1309. PMID: 18823406

Hanahan, D. and J. Folkman, 1996. Patterns and emerging mechanisms of the angiogenic switch during tumorigenesis. Cell, 86: 353-364. PMID: 8756718

Hanahan, D. and R.A. Weinberg, 2011. Hallmarks of cancer: The next generation. Cell, 144: 646-674. PMID: 21376230

Hanahan, D., G. Bergers and E. Bergsland, 2000. Less is more, regularly: Metronomic dosing of cytotoxic drugs can target tumor angiogenesis in mice. J. Clin. Invest., 105: 1045-1047. PMID: 10772648

Harris, S.G., J. Padilla, L. Koumas, D. Ray and R.P. Phipps, 2002. Prostaglandins as modulators of immunity. Trends Immunol., 23: 144-150. PMID: 11864843

Hattori, K., S. Dias, B. Heissig, N.R. Hackett and D. Lyden et al., 2000. Vascular endothelial growth factor and angiopoietin-1 stimulate postnatal hematopoiesis by recruitment of vasculogenic and hematopoietic stem cells. J. Exp. Med., 193: 10051014. PMID: 11342585
Heller, D.A., C.A. Clifford, M.H. Goldschmidt, D.E. Holt and F.S. Shofer et al., 2005. Cyclooxygenase-2 expression is associated with histologic tumor type in canine mammary carcinoma. Vet. Pathol., 42: 776-780. PMID: 16301573

Herschman, H.R., 2004. Regulation and Function of Prostaglandin Synthase 2/Cyclooxygenase. In: The Eicosanoids, Curtis-Prior, P., (Ed.)., John Wiley, West Sussex, UK., ISBN-10: 047002061X, pp: 43-52.

Impellizeri, J.A. and D.G. Esplin, 2008. Expression of cyclooxygenase- 2 in canine nasal carcinomas. Vet. J., 176: 408-410. PMID: 17517527

Isotani, M., N. Ishida, M. Tominaga, K. Tamura and H. Yagihara et al., 2008. Effect of tyrosine kinase inhibition by imatinib mesylate on mast cell tumors in dogs. J. Vet. Intern. Med., 22: 985-988. PMID: 18564222

Jurado-Garcia, J.M., A. Sanchez, B. Pajares, E. Perez and L. Alonso et al., 2008. Combined oral cyclophosphamide and bevacizumab in heavily pretreated ovarian cancer. Clin. Transl. Oncol., 10: 583586. PMID: 18796376

Kato, H., Y. Ichinose, M. Ohta, E. Hata and N. Tsubota et al., 2004. A randomized trial of adjuvant chemotherapy with uracil-tegafur for adenocarcinoma of the lung. N. Engl. J. Med., 350: 1713-1721. PMID: 15102997

Kato, Y., K. Asano, T. Mogi, K. Kutara and K. Teshima et al., 2007. Clinical significance of circulating vascular endothelial growth factor in dogs with mammary gland tumors. J. Vet. Med. Sci., 69: 7780. PMID: 17283406

Kenyon, B.M., F. Browne and R.J. D'Amato, 1997. Effects of thalidomide and related metabolites in a mouse corneal model of neovascularization. Exp. Eye Res., 64: 971-978. PMID: 9301478

Kerbel, R.S. and B.A. Kamen, 2004. The anti-angiogenic basis of metronomic chemotherapy. Nat. Rev. Cancer, 4: 423-436. PMID: 15170445

Kerbel, R.S., 1991. Inhibition of tumor angiogenesis as a strategy to circumvent acquired resistance to anticancer therapeutic agents. Bioessays, 13: 31-36. PMID: 1722975

Kerbel, R.S., 2012. Strategies for improving the clinical benefit of antiangiogenic drug based therapies for breast cancer. J. Mammary. Gland. Biol. Neoplasia. PMID: 23011602

Khan, K.N., D.W. Knapp, D.B. Denicola and R.K. Harris, 2000. Expression of cyclooxygeanse-2 in transitional cell carcinoma of the urinary bladder in dogs. Am. J. Vet. Res., 61: 478-481. PMID: 10803639 
Khan, K.N., K.M. Stanfield, D. Trakovic and D.W. Knapp, 2001. Expression of cyclooxygenase-2 in canine renal cell carcinoma. Vet. Pathol., 38: 116119. PMID: 11199159

Kleiter, M., D.E. Malarkey, D.E. Ruslander and D.E. Thrall, 2004. Expression of cyclooxygenase-2 in canine epithelial nasal tumors. Vet. Radiol. Ultrasound., 45: 255-260. PMID: 15200266

Klement, G., S. Baruchel, J. Rak, S. Man and K. Clark et al., 2000. Continuous low-dose therapy with vinblastine and VEGF receptor-2 antibody induces sustained tumor regression without overt toxicity. J. Clin. Invest., 105: R15-R24. PMID: 10772661

Knapp, D.W., R.C. Richardson, T.C.K. Chan, G.D. Bottoms and W.R. Widmer et al., 1994. Piroxicam therapy in 34 dogs with transitional cell carcinoma of the urinary bladder. J. Vet. Intern. Med., 8: 273278. PMID: 7983623

Knottenbelt, C., D. Mellor, C. Nixon, H. Thompson and D.J. Argyle, 2006. Cohort study of COX-1 and COX-2 expression in canine rectal and bladder tumours. J. Small. Anim. Pract., 47: 196-200. PMID: 16573762

Kong, D.S., J.I. Lee, W.S. Kim, M.J. Son and H.D. Lim et al., 2006. A pilot study of metronomic temozolomide treatment in patients with recurrent temozolomide-refractory glioblastoma. Oncol. Rep., 16: 1117-1121. PMID: 17016602

Krzyzanowska, M.K., I.F. Tannock, G. Lockwood, J. Knox and M. Moore et al., 2007. A phase II trial of continuous low-dose oral cyclophosphamide and celecoxib in patients with renal cell carcinoma. Cancer Chemother. Pharmacol., 60: 135-141. PMID: 17009033

L'Eplattenier, H.F., C.L. Lai, R.V.D. Ham, J. Mol and F.V. Sluijs et al., 2007. Regulation of COX-2 expression in canine prostate carcinoma: Increased COX-2 expression is not related to inflammation. J. Vet. Intern. Med., 21: 776-782. PMID: 17708399

Lana, S., L. U'Ren, S. Plaza, R. Elmslie and D. Gustafson et al., 2007. Continuous low-dose oral chemotherapy for adjuvant therapy of splenic hemangiosarcoma in dogs. J. Vet. Intern. Med., 21: 764-769. PMID: 17708397

Laquente, B., F. Vinals and J.R. Germa, 2007. Metronomic chemotherapy: An antiangiogenic scheduling. Clin. Transl. Oncol., 9: 93-98. PMID: 17329220

Leach, T.N., M.O. Childress, S.N. Greene, A.S. Mohamed and G.E. Moore et al., 2012. Prospective trial of metronomic chlorambucil chemotherapy in dogs with naturally occurring cancer. Vet. Comp. Oncol., 10: 102-112. PMID: 22236329
Lee, J.Y., S. Tanabe, H. Shimohira, Y. Kobayashi and T. Oomachi et al., 2007. Expression of cyclooxygenase-2, P-glycoprotein and multi-drug resistance-associated protein in canine transitional cell carcinoma. Res. Vet. Sci., 83: 210-216. PMID: 17316722

Lindblad-Toh, K., C.M. Wade, T.S. Mikkelsen, E.K. Karlsson and D.B. Jaffe et al., 2005. Genome sequence, comparative analysis and haplotype structure of the domestic dog. Nature, 438: 803-819. PMID: 16341006

London, C., 2004. Kinase inhibitors in cancer therapy. Vet. Comp. Oncol., 2: 177-193. PMID: 19379292

London, C.A., 2009. Tyrosine kinase inhibitors in veterinary medicine. Top. Companion Anim. Med., 24: 106-112. PMID: 19732728

London, C.A., A.L. Hannah, R. Zadovoskaya, M.B. Chien and C. Kollias-Baker et al., 2003. Phase I dose-escalating study of SU11654, a small molecule receptor tyrosine kinase inhibitor, in dogs with spontaneous malignancies. Clin. Cancer Res., 9: 2755-2768. PMID: 12855656

London, C.A., P.B. Malpas, S.L. Wood-Follis, J.F. Boucher and A.W. Rusk et al., 2009. Multi-center, placebo-controlled, double-blind, randomized study of oral toceranib phosphate (SU11654), a receptor tyrosine kinase inhibitor, for the treatment of dogs with recurrent (either local or distant) mast cell tumor following surgical excision. Clin. Cancer Res., 15: 3856-3865. PMID: 19470739

Lord, R., S. Nair, A. Schache, J. Spicer and N. Somaihah et al., 2007. Low dose metronomic oral cyclophosphamide for hormone resistant prostate cancer: A phase II study. J. Urol., 177: 2136-2140. PMID: 17509300

Maiolino, P., G.D. Vico and B. Restucci, 2000. Expression of vascular endothelial growth factor in basal cell tumours and in squamous cell carcinomas of canine skin. J. Comp. Pathol., 123: 141-145. PMID: 11032667

Mancuso, P., M. Colleoni, A. Calleri, L. Orlando and P. Maisonneuve et al., 2006. Circulating endothelialcell kinetics and viability predict survival in breast cancer patients receiving metronomic chemotherapy. Blood, 1082: 452-459. PMID: 16543470

Marchetti, V., M. Giorgi, A. Fioravanti, R. Finotello and S. Citi et al., 2012. First-line metronomic chemotherapy in a metastatic model of spontaneous canine tumours: A pilot study. Invest. New Drugs, 30: 1725-1730. PMID: 21509468 
Marconato, L., C. Leo, R. Girelli, S. Salvi and F. Abramo et al., 2009. Association between waste management and cancer in companion animals. J. Vet. Intern. Med., 23: 564-569. PMID: 19298612

Marconato, L., G. Bettini, C. Giacoboni, G. Romanelli and A. Cesari et al., 2008. Clinicopathological features and outcome for dogs with mast cell tumors and bone marrow involvement. J. Vet. Intern. Med., 22: 1001-1007. PMID: 18564225

Marconato, L., J. Buchholz, M. Keller, G. Bettini and P. Valenti et al., 2012. Multimodal therapeutic approach and interdisciplinary challenge for the treatment of unresectable head and neck squamous cell carcinoma in six cats: A pilot study. Vet. Comp. Oncol. PMID: 22443464

Masferrer, J.L., B.S. Zweifel, K. Seibert and P. Needleman, 1990. Selective regulation of cellular cyclooxygenase by dexamethasone and endotoxin in mice. J. Clin. Invest., 86: 1375-1379. PMID: 2120289

Matiasek, L.A., S.R. Platt, V. Adams, T.J. Scase and D. Keys et al., 2009. Ki-67 and vascular endothelial growth factor expression in intracranial meningiomas in dogs. J. Vet. Intern. Med., 23: 146151. PMID: 19175733

Miller, K.D., C.J. Sweeney and G.W. Sledge Jr., 2001. Redefining the target: Chemotherapeutics as antiangiogenics. J. Clin. Oncol., 19: 1195-1206. PMID: 11181686

Mitchell, L., D.H. Thamm and B.J. Biller, 2012. Clinical and immunomodulatory effects of toceranib combined with low-dose cyclophosphamide in dogs with cancer. J. Vet. Intern. Med., 26: 355-362. PMID: 22303814

Mohammed, S.I., K.N. Khan, R.S. Sellers, M.G. Hayek and D.B. DeNicola et al., 2004. Expression of cyclooxygenase-1 and 2 in naturally-occurring canine cancer. Prostaglandins Leukot. Essent. Fatty Acids, 70: 479-483. PMID: 15062852

Mohammed, S.I., P.F. Bennett, B.A. Craig, N.W. Glickman and A.J Mutsaers et al., 2002. Effects of the cyclooxygenase inhibitor, piroxicam, on tumor response, apoptosis and angiogenesis in a canine model of human invasive urinary bladder cancer. Cancer Res., 62: 356-358. PMID: 11809678

Mullins, M.N., S.E. Lana, W.S. Dernell, G.K. Ogilvie and S.J. Withrow et al., 2004. Cyclooxygenase-2 expression in canine appendicular osteosarcomas. J. Vet. Intern. Med., 18: 859-865. PMID: 15638270
Munoz, R., S. Man, Y. Shaked, C.R. Lee and J. Wong et al., 2006. Highly efficacious nontoxic preclinical treatment for advanced metastatic breast cancer using combination oral UFT-cyclophosphamide metronomic chemotherapy. Cancer Res., 66: 33863391. PMID: 16585158

Mutsaers, A.J., 2007. Chemotherapy: new uses for old drugs. Vet. Clin. North Am. Small Anim. Pract., 37: 1079-1090. PMID: 17950883

Mutsaers, A.J., 2009. Metronomic chemotherapy. Top. Companion Anim. Med., 24: 137-143. PMID: 19732732

Mutsaers, A.J., S.I. Mohammed, D.B. DeNicola, P.W. Snyder and N.W. Glickman et al., 2005. Pretreatment tumor prostaglandin E2 concentration and cyclooxygenase- 2 expression are not associated with the response of canine naturally occurring invasive urinary bladder cancer to cyclooxygenase inhibitor therapy. Prostaglandins Leukot. Essent. Fatty Acids, 72: 181-186. PMID: 15664302

Nannini, M., E. Nobili, R.D. Cicilia, G. Brandi and A. Maleddu et al., 2009. To widen the setting of cancer patients who could benefit from metronomic capecitabine. Cancer Chemother. Pharmacol., 64: 189-193. DOI: 10.1007/s00280-009-0930-z PMID: 19151974

Nelius, T., K. Rinard and S. Filleur, 2011. Oral/metronomic cyclophosphamide-based chemotherapy as option for patients with castrationrefractory prostate cancer: Review of the literature. Cancer Treat. Rev., 37: 444-455. PMID: 21277093

Orlando, L., A. Cardillo, R. Ghisini, A. Rocca and A. Balduzzi et al., 2006. Trastuzumab in combination with metronomic cyclophosphamide and methotrexate in patients with HER-2 positive metastatic breast cancer. BMC Cancer, 6: 225-225. PMID: 16978400

Ostrander, E.A., U. Giger and K. Lindblad-Toh, 2006. The Dog and its Genome. 1st Edn., Cold Spring Harbor Laboratory Press, New York, ISBN-10: 0879697423, pp: 584.

Paoloni, M.C. and C. Khanna, 2007. Comparative oncology today. Vet. Clin. North Am. Small Anim. Pract., 37: 1023-1032. PMID: 17950880

Park, S.T., J.W. Jang, G.D. Kim, J.A. Park and W. Hur et al., 2010. Beneficial effect of metronomic chemotherapy on tumor suppression and survival in a rat model of hepatocellular carcinoma with liver cirrhosis. Cancer Chemother. Pharmacol., 65: 10291037. PMID: 19701751 
Pasquier, E., M. Kavallaris and N. Andre, 2010. Metronomic chemotherapy: New rationale for new directions. Nat. Rev. Clin. Oncol., 7: 455-465. PMID: 20531380

Pasquier, E., N. Andre and D. Braguer, 2007. Targeting microtubules to inhibit angiogenesis and disrupt tumour vasculature: Implications for cancer treatment. Curr. Cancer Drug Targets, 7: 566-581. PMID: 17896922

Patruno, R., N. Arpaia, C.D. Gadaleta, L. Passantino and N. Zizzo et al., 2009. VEGF concentration from plasma-activated platelets rich correlates with microvascular density and grading in canine mast cell tumour spontaneous model. J. Cell. Mol. Med., 13: 555-561. PMID: 18429933

Penel, N., A. Adenis and G. Bocci, 2012. Cyclophosphamide-based metronomic chemotherapy: After 10 years of experience, where do we stand and where are we going? Crit. Rev. Oncol. Hematol., 82: 40-50. PMID: 21641231

Platt, S.R., T.J. Scase, V. Adams, L. Wieczorek and J. Miller et al., 2006. Vascular endothelial growth factor expression in canine intracranial meningiomas and association with patient survival. J. Vet. Intern. Med., 20: 663-668. PMID: 16734105

Pronovost, N., M.M. Suter, E. Mueller, J. Sirois and M. Dore, 2004. Expression and regulation of cyclooxygenase-2 in normal and neoplastic canine keratinocytes. Vet. Comp. Oncol., 2: 222-233. PMID: 19379296

Pryer, N.K., L.B. Lee, R. Zadovaskaya, X. Yu and J. Sukbuntherng et al., 2003. Proof of target for SU11654: Inhibition of KIT phosphorylation in canine mast cell tumors. Clin. Cancer Res., 9: 57295734. PMID: 14654558

Qiu, C., D.D. Lin, H.H. Wang, C.H. Qiao and J. Wang et al., 2008a. Quantification of VEGF-C expression in canine mammary tumours. Aust. Vet. J., 86: 279282. PMID: 18616481

Qiu, C.W., D.G. Lin, J.Q. Wang, C.Y. Li and G.Z. Deng, 2008b. Expression and significance of PTEN and VEGF in canine mammary gland tumours. Vet. Res. Commun., 32: 463-472. PMID: 18461467

Queiroga, F.L., A. Alves, I. Pires and C. Lopes, 2007. Expression of Cox-1 and Cox-2 in canine mammary tumors. J. Comp. Pathol., 136: 177-185. PMID: 17416236

Queiroga, F.L., I. Pires, M. Parente, H. Gregorio and C.S. Lopes, 2011. COX-2 over-expression correlates with VEGF and tumour angiogenesis in canine mammary cancer. Vet. J., 189: 77-782. PMID: 20675158
Queiroga, F.L., M.D. Perez-Alenza, G. Silvan, L. Pena and C. Lopes et al., 2005. Cox-2 levels in canine mammary tumors, including inflammatory mammary carcinoma: Clinicopathological features and prognostic significance. Anticancer Res., 25: 4269-4275. PMID: 16309227

Queiroz, G.F.D., M.L.Z. Dagli, S.A. Meira and J.M. Matera, 2012. Serum vascular endothelial growth factor in dogs with soft tissue sarcomas. Vet. Comp. Oncol. PMID: 22372675

Queiroz, G.F.D., M.L. Dagli, H. Fukumasu, A.A. Zavala and J.M. Matera, 2010. Vascular endothelial growth factor expression and microvascular density in soft tissue sarcomas in dogs. J. Vet. Diagn. Invest., 22: 105-108. PMID: 20093695

Reardon, D.A., A. Desjardins, J.J. Vredenburgh, S. Gururangan and J.H. Sampson et al., 2009. Metronomic chemotherapy with daily, oral etoposide plus bevacizumab for recurrent malignant glioma: A phase II study. Br. J. Cancer, 101: 19861994. PMID: 19920819

Rebuzzi, L., M. Willmann, K. Sonneck, K.V. Gleixner and S. Florian et al., 2007. Detection of Vascular Endothelial Growth Factor (VEGF) and VEGF receptors Flt-1 and KDR in canine mastocytoma cells. Vet. Immunol. Immunopathol., 115: 320-333. PMID: 17196258

Restucci, B., S. Papparella, P. Maiolino and G.D. Vico, 2002. Expression of vascular endothelial growth factor in canine mammary tumors. Vet. Pathol., 39: 488-493. PMID: 12126152

Ribatti, D., B. Nico and E. Crivellato, 2009. Morphological and molecular aspects of physiological vascular morphogenesis. Angiogenesis, 12: 101-111. PMID: 19130273

Ribatti, D., B. Nico, E. Crivellato, A.M. Roccaro and A. Vacca, 2007. The history of the angiogenic switch concept. Leukemia, 21: 44-52. PMID: 16990761

Rossmeisl, J.H., R.B. Duncan, W.R. Huckle and G.C. Troy, 2007. Expression of vascular endothelial growth factor in tumors and plasma from dogs with primary intracranial neoplasms. Am. J. Vet. Res., 68: 1239-1245. PMID: 17975980

Rossmeisl, Jr. J.H., J.L. Robertson, K.L. Zimmerman, M.A. Higgins and D.A. Geiger, 2009. Cyclooxygenase-2 (COX-2) expression in canine intracranial meningiomas. Vet. Comp. Oncol., 7: 173-180. PMID: 19691646 
Saloustros, E., K. Kalbakis, N. Vardakis, A. Kalykaki and G. Milaki et al., 2011. Metronomic vinorelbine plus bevacizumab as salvage therapy for patients with metastatic breast cancer. J. Buon., 16: 215-218. PMID: 21766488

Schmidt, B.R., N.W. Glickman, D.B.D. Nicola, A.E.D. Gortari and D.W. Knapp, 2001. Evaluation of piroxicam for the treatment of oral squamous cell carcinoma in dogs. J. Am. Vet. Assoc., 218: 17831786. PMID: 11394830

Shchemelinin, I., L. Sefc and E. Necas, 2006. Protein kinases, their function and implication in cancer and other diseases. Folia Biol. (Praha), 52: 81-100. PMID: 17089919

Shiomitsu, K., C.L. Johnson, D.E. Malarkey, A.F. Pruitt and D.E. Thrall, 2009. Expression of epidermal growth factor receptor and vascular endothelial growth factor in malignant canine epithelial nasal tumours. Vet. Comp. Oncol., 7: 106-114. PMID: 19453364

Sorenmo, K.U., M.H. Goldschmidt, F.S. Shofer, C. Goldkamp and J. Ferracone, 2004. Evaluation of cyclooxygenase- 1 and cyclooxygenase- 2 expression and the effect of cyclooxygenase inhibitors in canine prostatic carcinoma. Vet. Comp. Oncol., 2: 13-23. PMID: 19379307

Souza, C.H.D.M., E. Toledo-Piza, R. Amorin, A. Barboza and K.M. Tobias, 2009. Inflammatory mammary carcinoma in 12 dogs: Clinical features, cyclooxygenase-2 expression and response to piroxicam treatment. Can. Vet. J., 50: 506-510. PMID: 19436636

Steinbild, S., J. Arends, M. Medinger, B. Haring and A. Frost et al., 2007. Metronomic antiangiogenic therapy with capecitabine and celecoxib in advanced tumor patients results of a phase II study. Onkologie, 30: 629-635. PMID: 18063875

Stupp, R., W.P. Mason, M.J.V.D. Bent, M. Weller and B. Fisher et al., 2005. Radiotherapy plus concomitant and adjuvant temozolomide for glioblastoma. N. Engl. J. Med., 352: 987-996. PMID: 15758009

Takahashi, T., C. Kalka, H. Masuda, D. Chen and M. Silver et al., 1999. Ischemia- and cytokine-induced mobilization of bone marrow-derived endothelial progenitor cells for neovascularization. Nat. Med., 5: 434-438. PMID: 10202935

Tanaka, H., H. Matsushima, A. Nishibu, B.E. Clausen and A. Takashima, 2009a. Dual therapeutic efficacy of vinblastine as a unique chemotherapeutic agent capable of inducing dendritic cell maturation. Cancer Res., 69: 6987-6994. PMID: 19706755
Tanaka, H., H. Matsushima, N. Mizumoto and A. Takashima, 2009b. Classification of chemotherapeutic agents based on their differential in vitro effects on dendritic cells. Cancer Res., 69: 6978-6986. PMID: 19706756

Taylor, K.H., A.N. Smith, M. Higginbotham, D.D. Schwartz and D.M. Carpenter et al., 2007. Expression of vascular endothelial growth factor in canine oral malignant melanoma. Vet. Comp. Oncol., 5: 208-218. PMID: 19754779

Thamm, D.H., M.G. O'Brien and D.M. Vail, 2008. Serum vascular endothelial growth factor concentrations and postsurgical outcome in dogs with osteosarcoma. Vet. Comp. Oncol., 6: 126-132. PMID: 19178672

Tremblay, C., M. Dore, P.N. Boschler and J. Sirois, 1999. Induction of prostaglandin $\mathrm{G} / \mathrm{H}$ synthase-2 in a canine model of spontaneous prostatic adenocarcinomas. J. Natl. Cancer Inst., 91: 13981403. PMID: 10451445

Tripp, C.D., J. Fidel, C.L. Anderson, M. Patrick and C. Pratt et al., 2011. Tolerability of administration of lomustine in dogs with cancer. J. Vet. Intern. Med., 25: 278-284. PMID: 21314727

Troy, G.C., W.R. Huckle, J.H. Rossmeisl, D. Panciera and O. Lanz et al., 2006. Endostatin and vascular endothelial growth factor concentrations in healthy dogs, dogs with selected neoplasia and dogs with nonneoplastic diseases. J. Vet. Intern. Med., 20: 144-150. PMID: 16496934

Tsuji, M., S. Kawano, S. Tsujii, H. Sawaoka and M. Hori et al., 1998. Cyclooxygenase regulates angiogenesis induced by colon cancer cells. Cell, 93: 705-716. PMID: 9630216

Vane, J.R., 1971. Inhibition of prostaglandin synthesis as a mechanism of action for aspirin-like drugs. Nat. New. Biol., 23: 232-235. PMID: 5284360

Vogt, T., C. Hafner, K. Bross, F. Bataille and K.W. Jauch et al., 2003. Antiangiogenetic therapy with pioglitazone, rofecoxib and metronomic trofosfamide in patients with advanced malignant vascular tumors. Cancer, 98: 2251-2256. PMID: 14601096

Wakeling, A.E., 2005. Inhibitors of growth factor signalling. Endocr. Relat. Cancer, 12: 183-187. PMID: 16113095

Wanebo, H.J., A. Argiris, E. Bergsland, S. Agarwala and H. Rugo, 2006. Targeting growth factors and angiogenesis; using small molecules in malignancy. Cancer Metastasis Rev., 25: 279-292. PMID: 16770540 
Weerdt, O.D., N.K.V.D. Donk, G. Veth, A.C. Bloem and A. Hagenbeek et al., 2001. Continuous low-dose cyclophosphamide-prednisone is effective and well tolerated in patients with advanced multiple myeloma. Neth. J. Med., 59: 50-56. PMID: 11476912

Wergin, M.C. and B. Kaser-Hotz, 2004. Plasma Vascular Endothelial Growth Factor (VEGF) measured in seventy dogs with spontaneously occurring tumours. In Vivo, 18: 15-19. PMID: 15011746

Wolfesberger, B., A.G.D. Arespacohaga, M. Willmann, W. Gerner and I. Miller et al., 2007. Expression of vascular endothelial growth factor and its receptors in canine lymphoma. J. Comp. Pathol., 137: 30-40. PMID: 17467003

Wolfesberger, B., I. Walter, C. Hoelzl, J.G. Thalhammer and M. Egerbacher, 2006. Antineoplastic effect of the cyclooxygenase inhibitor meloxicamon canine osteosarcoma cells. Res. Vet. Sci., 80: 308-316. PMID: 16182328

Wolfesberger, B., Z. Tonar, A. Fuchs-Baumgartinger, I. Walter and M. Skalicky et al., 2012. Angiogenic markers in canine lymphoma tissues do not predict survival times in chemotherapy treated dogs. Res. Vet. Sci., 92: 444-450. PMID: 21596405

Wolfesberger, B., Z. Tonar, K. Witter, A.G.D. Arespacohaga and M. Skalicky et al., 2008. Microvessel density in normal lymph nodes and lymphomas of dogs and their correlation with vascular endothelial growth factor expression. Res. Vet. Sci., 85: 56-61. PMID: 17888471
Wong, N.S., R.A. Buckman, M. Clemons, S. Verma and S. Dent et al., 2010. Phase I/II trial of metronomic chemotherapy with daily dalteparin and cyclophosphamide, twice-weekly methotrexate and daily prednisone as therapy for metastatic breast cancer using vascular endothelial growth factor and soluble vascular endothelial growth factor receptor levels as markers of response. J. Clin. Oncol., 28: 723-730. PMID: 20026801

Wortmann, S., M. Quinkler, C. Ritter, M. Kroiss and S. Johanssen et al., 2010. Bevacizumab plus capecitabine as a salvage therapy in advanced adrenocortical carcinoma. Eur. J. Endocrinol., 162: 349-356. PMID: 19903796

Yonemaru, K., H. Sakai, M. Murakami, T. Yanai and T. Masegi, 2006. Expression of vascular endothelial growth factor, basic fibroblast growth factor and their receptors (flt-1, flk-1 and flg-1) in canine vascular tumors. Vet. Pathol., 43: 971-980. PMID: 17099154

Young, S.D., M. Whissell, J.C. Noble, P.O. Cano and P.G. Lopez et al., 2006. Phase II clinical trial results involving treatment with low-dose daily oral cyclophosphamide, weekly vinblastine and rofecoxib in patients with advanced solid tumors. Clin. Cancer Res., 12: 3092-3098. PMID: 16707607

Zizzo, N., R. Patruno, F.A. Zito, A.D. Summa and A. Tinelli et al., 2010. Vascular endothelial growth factor concentrations from platelets correlate with tumor angiogenesis and grading in a spontaneous canine non-Hodgkin lymphoma model. Leuk. Lymphoma, 51: 291-296. PMID: 20001231 